\title{
Mesoscale modeling and simulation of microstructure evolution during dynamic recrystallization of a Ni-based superalloy
}

\author{
Fei Chen ${ }^{1,2} \cdot$ Zhenshan $\mathrm{Cui}^{2} \cdot$ Hengan $\mathrm{Ou}^{1} \cdot$ Hui Long ${ }^{3}$
}

Received: 3 June 2016/Accepted: 28 August 2016/Published online: 14 September 2016

(c) The Author(s) 2016. This article is published with open access at Springerlink.com

\begin{abstract}
Microstructural evolution and plastic flow characteristics of a Ni-based superalloy were investigated using a simulative model that couples the basic metallurgical principle of dynamic recrystallization (DRX) with the twodimensional (2D) cellular automaton (CA). Variation of dislocation density with local strain of deformation is considered for accurate determination of the microstructural evolution during DRX. The grain topography, the grain size and the recrystallized fraction can be well predicted by using the developed CA model, which enables to the establishment of the relationship between the flow stress, dislocation density, recrystallized fraction volume, recrystallized grain size and the thermomechanical parameters.
\end{abstract}

\section{Introduction}

The mechanical properties of a metallic component such as high-temperature alloy are largely depended on their chemical composition and microstructures, resulting from processing and heat treatment history in industrial production. Accurate prediction and precise control of the

Hengan $\mathrm{Ou}$

H.Ou@ nottingham.ac.uk

1 Department of Mechanical, Materials and Manufacturing Engineering, University of Nottingham, Nottingham NG7 2RD, UK

2 Institute of Forming Technology and Equipment, Shanghai Jiao Tong University, 1954 Huashan Road, Shanghai 200030, People's Republic of China

3 Department of Mechanical Engineering, University of Sheffield, Sheffield S1 3JD, UK microstructural evolution are of great importance for designers to achieve excellent mechanical properties for metals and alloys through hot working. Up to date, DRX has been recognized as a powerful mechanism for grain refinement under hot plastic deformation. In this context, in-depth understanding of microstructural evolution during DRX can help develop more accurate prediction methods to simulate microstructural characterization and mechanical properties in the hot deformation of metals and alloys [1-3].

With the rapid development of computer technology and a thorough understanding of microstructural evolution thermodynamics and kinetics, mesoscale methods, i.e., the CA method, Monte Carlo (MC) method, vertex models, phase-field approach and level-set modeling, have been successfully used to simulate microstructural evolution in hot working. Mesoscale models can not only predict the general average microstructure properties (the kinetics of recrystallization and grain size), but also able to visually provide the virtual microstructural evolution during hot deformation. Compared with the other methods, CA method can be used as an alternative approach to describe the spatial and temporal microstructure evolution on a mesoscale. There are some shortcomings of CA method. For example, CA has poor representation of grain boundary curvature as compared to the phase-field model and levelset model. The first attempt to model of microstructural evolution during DRX by CA method was made by Goetz and Seetharaman [4]. Up to now, there are many cases of successful application of CA in modeling microstructural evolution. In these studies, Ding et al. [5], Raabe [6], Kugler and Turk [7], Xiao and Zheng [8] and Jin and Cui [9] contributed greatly to the development of the CA method for the simulation of DRX from the aspects of optimization algorithm, grain morphology change and 
parameter identification. Recently, based on the work of Ding et al. [5] and Kugler and Turk [7], Yazdipour et al. [10] simulated DRX during thermomechanical deformation of 304 austenitic stainless steel by the CA method. In this case, initial grain size, initial grain orientation and dislocation density are used as input data to the CA model; the flow curve, dislocation density, finial grain size and orientation and recrystallized fraction are the output data. Hallberg et al. [11] employed the CA model with probabilistic cell switches in simulating DRX of pure $\mathrm{Cu}$. Ding et al. [12] investigated the hot compression behavior of the Mg-9Al-1Zn alloy using EBSP analysis and the CA method. Chen et al. [13, 14] predicted microstructural evolution during DRX of an ultra-super-critical rotor steel. In addition, the DRX behavior of TRIP steel [15], C-Mn micro-alloy steel [16], Ti-alloy [17] and Ni-based alloy [18] was studied by using improved CA models. However, in order to perfect the classical CA model for DRX, the following two aspects still need further investigation. Firstly, it is highly necessary to develop reasonable and practicable method to calculate CA simulation constants such as nucleation parameter. Secondly, it is desirable to introduce the mechanisms of grain morphology change on the nucleation and grain growth during DRX in either twodimensional or three-dimensional cases.

Due to its excellent mechanical characteristics at elevated temperatures up to $650{ }^{\circ} \mathrm{C}$, good fatigue and corrosion resistance, Ni-based superalloy named IN 718 has been widely used in aerospace industry [19]. Usually, IN718 superalloy components are processed by hot forging. The mechanical properties of forgings are extremely sensitive to the dynamic and interconnected variables, such as strain, strain rate and temperature [20]. Therefore, in recent years, the flow behaviors and microstructural evolution of IN718 have been studied experimentally by many researchers [21-26]. However, there have been few investigations on modeling and simulation of microstructure evolution for IN718 superalloy during hot working. In order to deeply understand DRX mechanism and to predict and control the microstructure evolution during DRX for IN718, there is a need to develop new model to simulate the grain refinement during hot working from mesoscale aspect.

The main purpose of this article is to develop a 2D CA model to predict the microstructure evolution for IN718 superalloy during hot working. The CA model has the following advantages. Firstly, reverse algorithm was adopted for parameter identification. Secondly, grain morphology deformation technique was used in the CA model, in which a cellular coordinate system (CCS) and a material coordinate system (MCS) were established separately. The CCS remains unchangeable in the whole simulation. The MCS and the corresponding grain boundary shape change with deformation in the developed DRX module. By using the developed model, a wide range of deformation temperature and strain rate over DRX were examined to investigate the quantitative and topographic prediction of the microstructural evolution during hot working for IN718 superalloy. As a result, the appropriate hot working parameters for IN718 were recommended based on the CA simulations.

\section{Experiment}

\subsection{Experiment materials and procedures}

The chemical composition (wt\%) of IN718 superalloy used in this study is as follows: $18.07 \mathrm{Cr}-17.74 \mathrm{Fe}-5.41 \mathrm{Nb}$ 2.86Mo-1.02Ti-0.9Si-0.5Al-0.025C-(bal.)Ni. The diameter and length of the specimens are $8 \mathrm{~mm}$ and $12 \mathrm{~mm}$, respectively. According to ISO 6892-2, suitable test procedures were designed. All the specimens were solution treated at $1100{ }^{\circ} \mathrm{C}$ for $0.75 \mathrm{~h}$ and then cooled to room temperature in the air. The isothermal compression tests were carried out at the temperatures of 940, 980, 1020 and $1060{ }^{\circ} \mathrm{C}$ and at the strain rates of $0.001,0.01,0.1$ and $1 \mathrm{~s}^{-1}$. The tests were performed on a Gleeble-1500 thermomechanical simulator. Before loading, the specimens were heated to the test temperature with the heating rate of $10{ }^{\circ} \mathrm{C} / \mathrm{min}$. The maximum true strain is 1.0 . In order to study the effects of forming process on the microstructure, the specimens were immediately quenched by water after hot compression. The deformed specimens were sliced along the compression axis section for microstructural analysis. The tested specimens were prepared for optical microscopy (OM) using standard metallographic techniques of mounting, coarse and fine grinding, final polishing and etching. The specimens were immersion etched with HCL $(20 \mathrm{ml})+40 \% \mathrm{HF}(50 \mathrm{ml})+\mathrm{H}_{2} \mathrm{O}_{2}(2 \mathrm{ml})$ to reveal the microstructures. Etching times varied with test conditions from 2 to $3 \mathrm{~min}$ at room temperature. As shown in Fig. 1, the optical microstructures in the section plane are examined. The average grain sizes for the nine positions at axial section are measured using the method described in ASTM standards.

\subsection{Flow characteristics}

Figure 2 shows the true stress-true strain curves of IN718 superalloy obtained at the strain rates of $0.001,0.01,0.1$ and $1 \mathrm{~s}^{-1}$ and temperatures from 940 to $1060{ }^{\circ} \mathrm{C}$. As shown in Fig. 2, it is easily found that at the beginning of deformation, the flow stress increases rapidly. It is attributed to the high work hardening rate caused by the rapid generation and multiplication of dislocation. Meanwhile, 


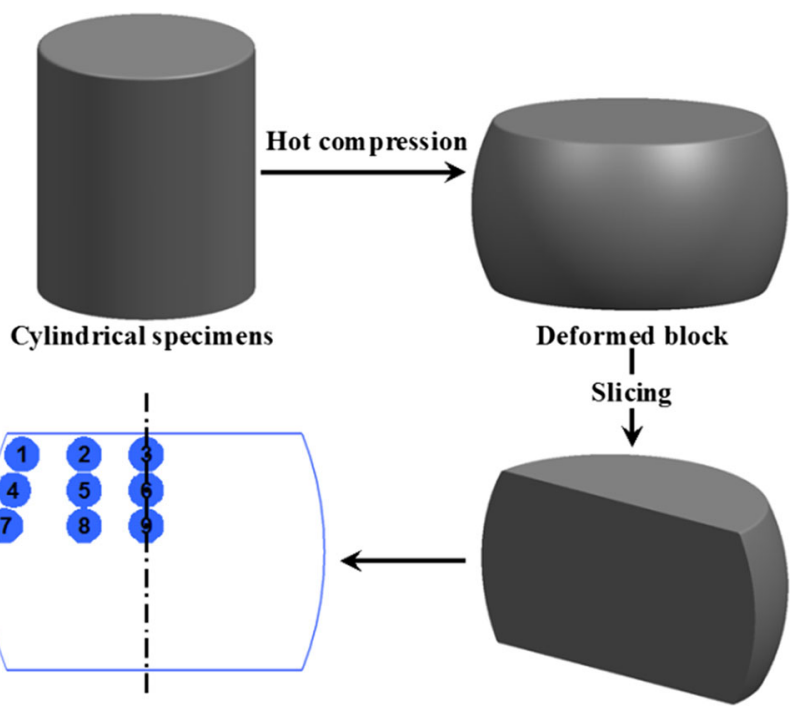

Fig. 1 Nine positions at axial section for optical microstructure analysis

the dynamic recovery resulted from the dislocation climbing, and sliding is too weak to overcome the work hardening effect. With the increase in strain, the flow stress curves exhibit similar trends, i.e., a single peak at a critical strain followed by a strain softening stage and then sometimes a steady stage at high strain zone. The characteristics of the flow stress curves are typical that can be observed in many metals and alloys. This implies the occurrence of DRX phenomenon during hot deformation.
However, at temperatures from 940 to $1060{ }^{\circ} \mathrm{C}$ and strain rate of $1 \mathrm{~s}^{-1}$, there is no obvious steady stage in the test strain range.

\section{Modeling and simulation on DRX by CA method}

\subsection{Mechanism of CA simulation of DRX}

When CA method is adopted, the evolution of the microstructure can be represented by some basic microstructural constituents such as the grain orientation. This means that the actual microstructures can be predicted at mesoscale and the statistical information of internal variables used in the macroscale models are just the inevitable results. The interaction mechanism between mesoscopic and macroscopic evolution for CA simulation is illustrated in Fig. 3. Actually, the dislocation density provides a link of multi-scale modeling to bridge the macroscopic thermomechanical parameters and the mesoscopic microstructures. Figure 3 also schematically shows the variation of flow stress as well as the mean dislocation density of the material and instantaneous dislocation density at a single cell of CA. In the case of none recrystallization, the flow stress depends on the combined effects of work hardening and dynamic recovery, showing a monotone increase toward a saturated stress. But in fact, DRX takes place once the dislocation density reaches a critical value, resulting in a significant decrease in the dislocation
Fig. 2 True stress-strain curves of IN718 superalloy deformed at different deformation conditions: a $\dot{\varepsilon}=0.001 \mathrm{~s}^{-1}, \mathbf{b}$ $\dot{\varepsilon}=0.01 \mathrm{~s}^{-1}, \mathbf{c} \dot{\varepsilon}=0.1 \mathrm{~s}^{-1}$ and $\mathbf{d} \dot{\varepsilon}=1 \mathrm{~s}^{-1}$
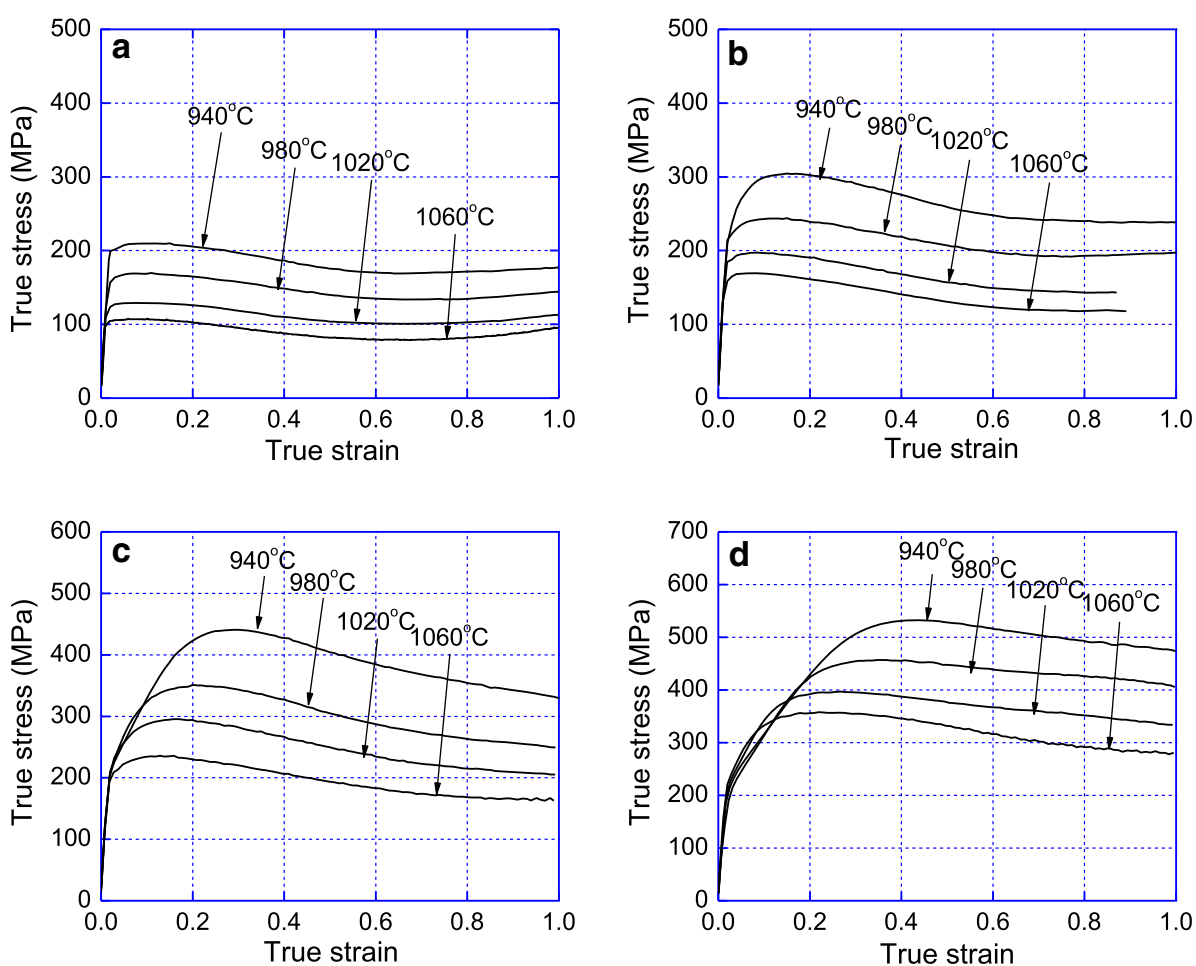
Fig. 3 Interaction mechanism between mesoscopic and macroscopic evolution for CA simulation

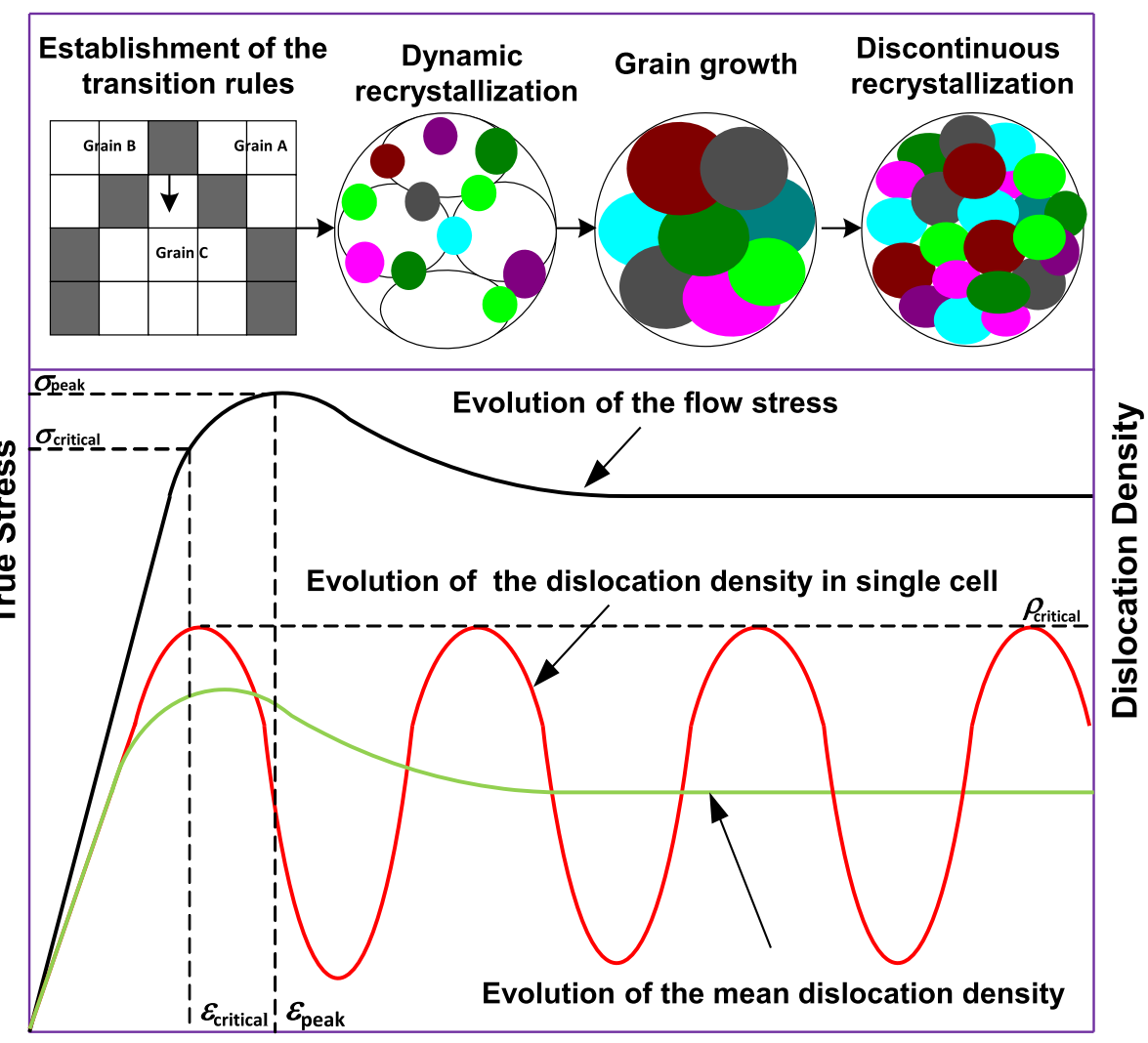

True Strain density in the recrystallized zone. The difference between the dislocation density of recrystallized grain and the matrix supplies the thermodynamic driving force for the growth of recrystallized grain. In continuous deformation, the dislocation density of a particle changes as the strain increases and the recrystallization happens, which shows a decreased mean dislocation density and a decreased flow stress. Therefore, when the CA method is adopted, one of the most important issues is to track the changes in dislocation density.

\subsection{Modeling of dislocation evolution}

During plastic deformation, dislocations are created by work hardening $(\mathrm{WH})$ and annihilated by dynamic recovery (DRV). To describe the deformation behavior of austenite, the Kocks-Mecking model [27] is employed, in which the flow stress is proportional to the square root of dislocation density as given in:

$\sigma=\alpha \mu b \sqrt{\rho_{\text {mean }}}$

where $\alpha$ is a dislocation interaction term, which is around 0.5 for most metals, $b$ is Burger's vector, $\mu$ is the shear modulus, $\rho_{\text {mean }}$ is the mean dislocation density. In CA simulation, $\rho_{\text {mean }}$ can be expressed as: $\rho_{\text {mean }}=\frac{1}{N_{\text {total }}} \sum_{i, j} \rho_{i, j}$

where $N_{\text {total }}$ is the total number of cells in a CA model and $\rho_{i, j}$ is the dislocation density of site $(i, j)$. The dislocation hardening and recovery are modeled by the change in the dislocation density exactly as proposed by Estrin [28]. The variation of the dislocation density of site $(i, j)$ with respect to strain can be expressed as:

$\frac{\mathrm{d} \rho_{i, j}}{\mathrm{~d} \varepsilon}=k_{1} \sqrt{\rho_{i, j}}-k_{2} \rho_{i, j}$

where the two terms represent a competition between storage of mobile dislocations and dynamic annihilation of dislocations, $k_{1}$ represents work hardening, $k_{2}$ is the softening parameter that represents the recovery of dislocation. $k_{1}$ and $k_{2}$ in Eq. (3) can be evaluated from the measured flow stress and can be expressed as functions of temperature and strain rate.

\subsection{Modeling of nucleation and grain growth}

The onset of nucleation of DRX is usually associated with the accumulation of dislocations. When the dislocation density of a deforming matrix reaches a critical value 
( $\left.\rho_{\text {critical }}\right)$ during thermomechanical processing, nucleation of DRX is initiated. $\rho_{\text {critical }}$ is calculated by using Eq. (1). Nucleation of DRX is handled by randomly choosing a certain fraction of the total cells located on grain boundaries (including primary grain boundaries and recrystallized grain boundaries) as the new nucleus at each CA simulation step. Each nucleus consists of one cell. The orientations of the nucleus are randomly set in the program and are represented by random integer in the range of 1180. When such a nucleus is placed in the system, it is initially assigned a stored energy of zero and increases with increasing strain based on Eq. (3). The nucleation rate per unit grain boundary area for DRX can be expressed as [5]:

$N_{\text {dynamic }}=C_{\text {dynamic }} \dot{\varepsilon}^{m} \exp \left(-\frac{Q_{\text {act }}}{R T}\right)$

where $C_{\text {dynamic }}$ is a constant, $m$ is set to 1.0 in the present simulation, $Q_{\text {act }}$ is the activation energy, $\dot{\varepsilon}$ is the strain rate, $R$ is the universal gas constant $\left(8.31 \mathrm{~J} \mathrm{~mol}^{-1} \mathrm{~K}^{-1}\right)$ and $T$ is the absolute temperature. There are two basic methods to calculate the constant $\left(C_{\text {dynamic }}\right)$. First, the percentage of $\operatorname{DRX}(\eta)$ can be experimentally measured for a specific deformation condition [8]; then, the constant $C_{\text {dynamic }}$ in Eq. (4) can be determined for a deforming material. Second, the constant $C_{\text {dynamic }}$ can be determined using an inverse analysis method [9, 14]. The dislocation density of recrystallized grain evolves from zero to a saturated value. The difference between the dislocation densities of recrystallized grain and the matrix supplies the thermodynamic driving force for the growth of recrystallized grain. It is generally assumed that the velocity of grain boundary movement $(v)$ fulfills the following equation [29]:

$v=M \Delta f$

where $\Delta f$ is the driving force and $M$ is the grain boundary mobility, which can be calculated by the following equation:

$M=\frac{\delta D_{\mathrm{ob}} b}{K T} \exp \left(-\frac{Q_{\mathrm{b}}}{R T}\right)$

where $\delta$ is the characteristic grain boundary thickness, $D_{\mathrm{ob}}$ is the boundary self-diffusion coefficient, $Q_{\mathrm{b}}$ is the grain boundary diffusion activation energy, and $K$ is the Boltzmann's constant.

It is assumed that the recrystallized grain is spherical. The driving force $\Delta f$ can be expressed as:

$\Delta f=\tau\left(\rho_{\text {matrix }}-\rho_{R-\text { grain }}\right)-2 \gamma_{i} / r_{i \_ \text {recrystallized }}$

where $\rho_{\text {matrix }}$ is the dislocation density of the matrix, $\rho_{\mathrm{R} \text {-grain }}$ is the dislocation density of the $i$ th recrystallized grain, $\tau$ is the dislocation line energy $\left(\tau=c \mu b^{2}\right.$ ) ( $c$ is a constant equal to 0.5 ). The $2 \mathrm{D}$ simulation metallography is viewed as a cross section of the corresponding 3D microstructure. An equivalent average radius of a grain $\left(r_{i \_ \text {recrystallized }}\right)$ is used to define the recrystallized grain size and is calculated by using the following equation:

$r_{i \_ \text {recrystallized }}=\sqrt{\frac{N_{i} A_{\text {cell }}}{\pi}}$

where $N_{i}$ is the total number of cells belonging to the recrystallized grain and where $A_{\text {cell }}$ is the area of one cell. Besides, the grain boundary energy $\left(\gamma_{\mathrm{i}}\right)$ can be calculated by the Read-Shockley equation. The time step $(\Delta t)$ is defined as the ratio of the cell diameter $\left(d_{0}\right)$ to maximum grain boundary velocity $\left(v_{\max }\right)$.

\subsection{Consideration of grain geometry of real deformation}

The deformation of grain geometry makes change of grain boundary and consequently affects nucleation and growth of nuclei during DRX. To describe the effect of compression on the grain shape more accurately, a 2D CA model with the incorporation of a grain morphology deformation technique was adopted in this study. In the modified CA model, a cellular coordinate system and a material coordinate system were established separately. The cellular coordinate system was used to describe the nucleation of DRX and the growth of new recrystallized grains; the size of the cell remains unchangeable. The material coordinate system and the corresponding grain boundary shape change with deformation during a CA simulation. A detail description of grain morphology mechanism in CA simulation is shown in Fig. 4. As shown in this figure (step 1), the original matrix was compressed in the compression direction and elongated in the perpendicular direction during DRX. Then, the grain boundary will be mapped from the material coordinate system to the cellular coordinate system before the appearance of DRX (step 2). The dislocation density increases gradually, and when the value reaches a critical density ( $\left.\rho_{\text {critical }}\right)$, new nucleus appears on the grain boundaries and continues to grow with the model of equiaxed growth in the cellular coordinate system (step 3). Finally, the grain boundary will be mapped back to the material coordinate system for the next round of the simulation.

\subsection{Implementation of recrystallization in CA model}

In this study, the CA framework for recrystallization is composed of the following parts:

(1) Generation of initial microstructure;

(2) Definition of the cell neighborhood; 

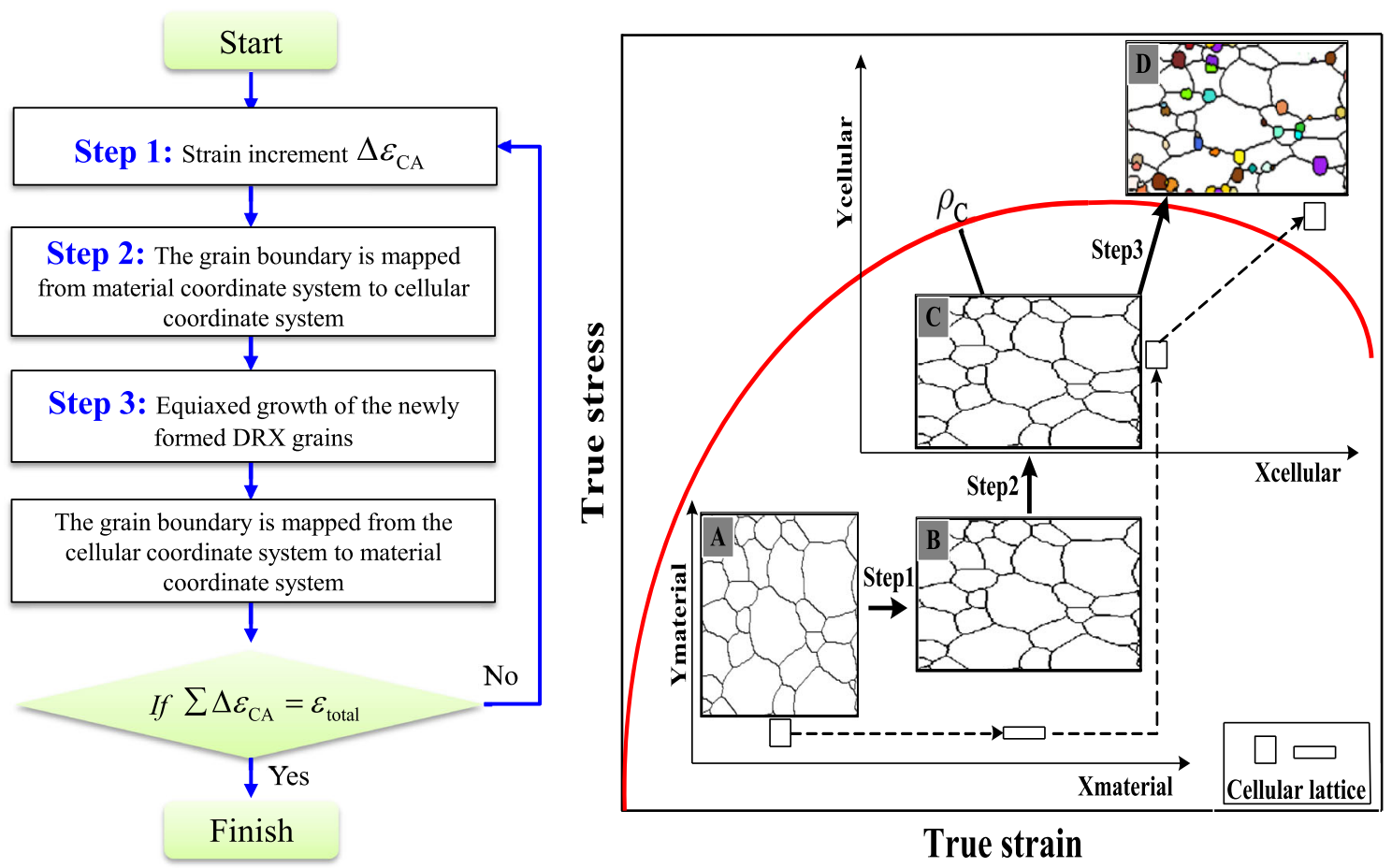

Fig. 4 A schematic representation showing the mapping of the grain boundary through material cellular coordinate transformation

(3) Assignment of state variables to each cell;

(4) Definition of transition rules for CA models.

Every cell has four state variables:

(1) The dislocation density variable represents the stored energy. The initial dislocation density of all primary grains is uniform and identical. During the progress of DRX, the dislocation density increment $(\Delta \rho)$ is calculated based on Eq. (3). When a cell recrystallized, the dislocation density of the cell is equal to $\rho_{\text {initial }}$ and increases with increasing strain.

(2) The grain orientation variable represents different grains.

(3) The grain boundary variable indicates whether the cell locates on the grain boundary.

(4) The fraction variable $\left(f_{i, j}^{t}\right)$ represents the recrystallized fraction, which can be calculated as $f_{i, j}^{t}=l_{i, j}^{t} / l_{0}$. The increase in the distance of grain boundary $\left(l_{\mathrm{i}, \mathrm{j}}^{\mathrm{t}}\right)$ at time $t$ can be calculated as $l_{i, j}^{t}=l_{i, j}^{t-\Delta t}+v \Delta t$, where $l_{i, j}^{t-\Delta t}$ indicates the increment of the distance at $t-\Delta t$ When a cell recrystallized, the recrystallized fraction of the cell equals to 1 .

In the CA model for recrystallization, the transformation of a cell from the unrecrystallized state to the recrystallized state can be initiated when the following conditions are fulfilled simultaneously:
(1) The driving force is positive;

(2) The cell is at the grain boundary; meanwhile, at least one cell in the von Neumann neighborhood is already in the recrystallized state;

(3) The recrystallized fraction variable is equal to 1 ;

(4) The computer-generated random number is less than the transformation probability $P$, which is defined as $P=i / 4$, where $i$ is the number of neighboring cells, which have the same orientation in the von Neumann neighborhood.

Figure 5 gives the operation of the CA model. Generally, it includes the following steps:

(1) The initial grain is generated by running the initial microstructure generation $\mathrm{CA}$ module based on the state transition rules. In this module, two of four state variables are used: the orientation variable and grain boundary variable. As shown in Fig. 5, the initial orientation of the matrix is randomly set as $Q(1 \leqq Q \leqq 180)$. In each cellular automaton steps (CASs), the entire cells are investigated in accordance with the transition rules. More details on the transition rules can be found in previous work [30].

(2) Calculation of the time step by the following Eq. (9). The time step is defined as the ratio of the cell diameter $\left(d_{0}\right)$ to maximum grain boundary velocity $\left(v_{\max }\right)$. 


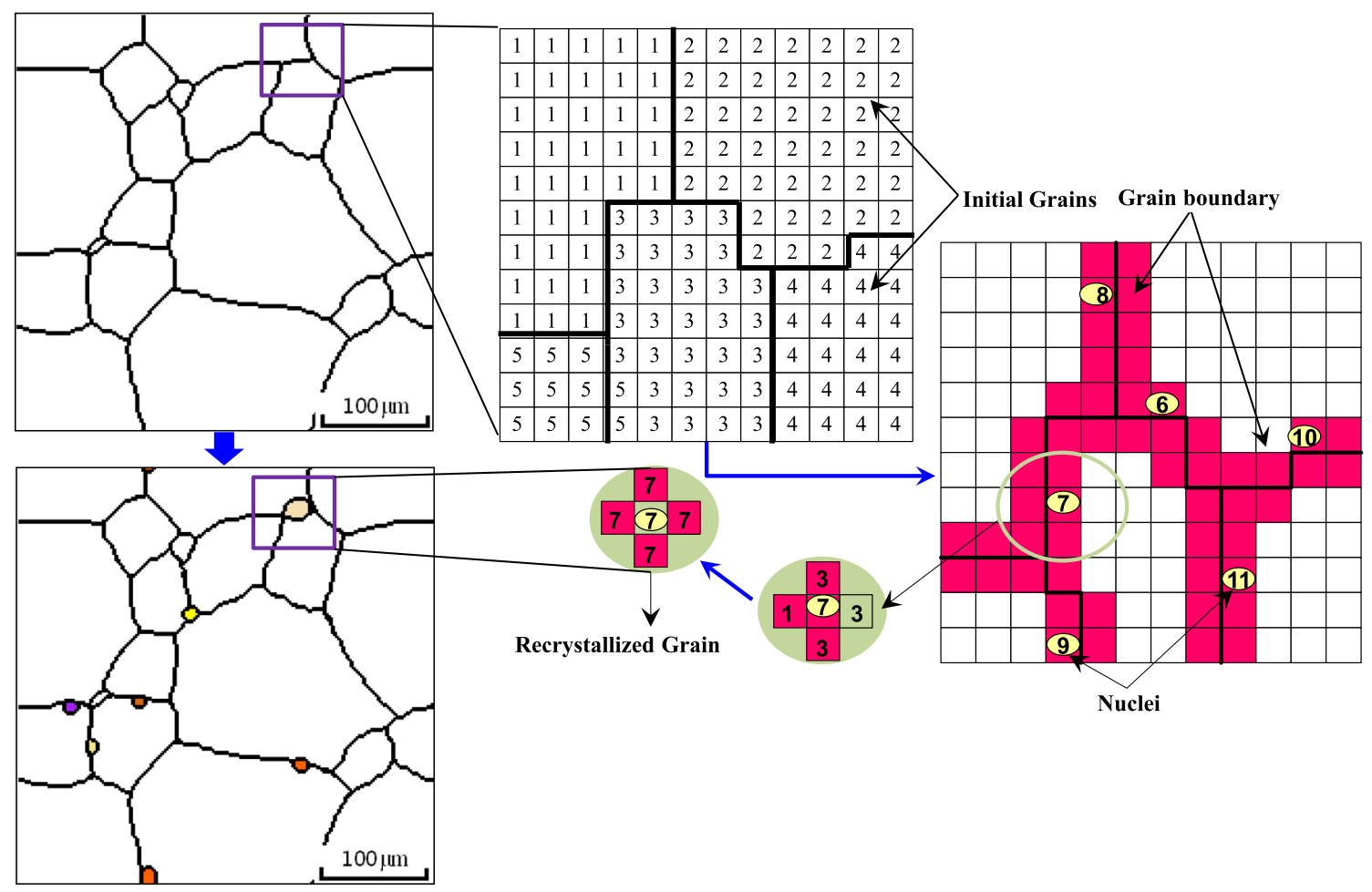

Fig. 5 Illustration of operation of CA mode for dynamic recrystallization

$\Delta t=\frac{d_{0}}{v_{\max }}=\frac{k_{2}^{2} d_{0}}{M \tau k_{1}^{2}}$

The total number of cycles can be determined by $\varepsilon / \dot{\varepsilon} \Delta t$ in the whole deformation.

(3) Calculation of dislocation density increment with the deformation by Eq. (3). When the dislocation density of the matrix reaches a critical value ( $\left.\rho_{\text {critical }}\right)$ for $\mathrm{DRX}$, the recrystallized nuclei form on the grain boundaries as shown in Fig. 5.

(4) Once recrystallization occurs in a cell, the density of the cell comes back to the relative low density, which is equal to $\rho_{\text {initial }}$ in this CA simulation.

(5) Growth of the recrystallized nuclei toward to the recrystallized cells with the model of equiaxed growth method.

\section{CA simulation parameters}

\subsection{Parameter categories}

The parameters used in the modified CA simulation are divided into two categories:

(1) The material parameters calculated from the flow stress obtained by compression tests, such as $k_{1}$ and $k_{2}$ in Eq. (3), the critical dislocation density ( $\left.\rho_{\text {critical }}\right)$ for DRX and the nucleation parameter $N_{\text {dynamic }}$.

(2) The physical metallurgy parameters of IN718 superalloy obtained from the reference. The values of the physical metallurgy parameters for IN718 are listed in Table 1.

\subsection{Determination of $k_{1}$ and $k_{2}$}

Equation (3) describes the variation of dislocation density without the occurrence of DRX. Therefore, $k_{1}$ and $k_{2}$ can be determined from the measured stress-strain data before the onset of DRX. By integrating Eq. (3), the following expression is obtained,

$\rho=\left(\frac{k_{1}}{k_{2}}-\frac{k_{1}}{k_{2}} e^{-\frac{k_{2}}{2} \varepsilon}+\sqrt{\rho_{0}} e^{-\frac{k_{2}}{2} \varepsilon}\right)^{2}$

where $\rho_{0}$ is calculated using Eq. (1) and $\sigma_{0}$ is obtained

Table 1 Physical metallurgy constants for IN718 superalloy $[31,32]$

\begin{tabular}{ll}
\hline Parameters & Values \\
\hline$\mu_{0}\left(\mathrm{MN} / \mathrm{m}^{2}\right)$ & $7.89 \times 10^{4}$ \\
$Q_{\mathrm{b}}(\mathrm{kJ} / \mathrm{mol})$ & 287 \\
$\delta D_{\mathrm{ob}}\left(\mathrm{m}^{3} / \mathrm{s}\right)$ & $1.34 \times 10^{-11}$ \\
$b(\mathrm{~m})$ & $2.49 \times 10^{-10}$ \\
\hline
\end{tabular}


from the flow stress. Once $\frac{\mathrm{d} \rho}{\mathrm{d} \varepsilon}=0$, it can be obtained,

$\rho_{\text {saturation }}=\left(\frac{k_{1}}{k_{2}}\right)^{2}$

where $\rho_{\text {saturation }}$ is the saturation dislocation density. Substituting Eq. (11) into Eq. (10), it gives

$\sigma_{\mathrm{WH}}=\sigma_{\text {saturation }}+\left(\sigma_{0}-\sigma_{\text {saturation }}\right) e^{-\frac{k_{2}}{2} \varepsilon}$

where $\sigma_{\mathrm{WH}}$ is the flow stress in the working hardening stage. For a certain deformation condition, substituting $\sigma_{\mathrm{WH}}, \sigma_{0}$ and $\sigma_{\text {saturation }}$ into Eq. (12), it gives the value of $k_{2}$. From Eq. (11), the value of $k_{1}$ can be obtained.

$k_{1}=\left(\frac{1}{\alpha \mu b}\right) \sigma_{\text {saturation }} k_{2}$

To calculate $\sigma_{\text {saturation }}$ and $\rho_{\text {critical }}$ on the flow curve, the approach based on the analysis by Kocks and Mecking was employed [27]. Using this method, the critical and saturation stress for dynamic recrystallization can be indirectly determined from the curve of working hardening rate $(\theta=\mathrm{d} \sigma / \mathrm{d} \varepsilon)$. Figure 6 gives the stress dependence of the experimental work hardening rate at different deformation conditions. As an example $\left(940{ }^{\circ} \mathrm{C}\right.$ and $\left.1 \mathrm{~s}^{-1}\right)$, the key points have been marked by red circle in Fig. 6 .

\subsection{Calculation of work hardening rate and the activation energy}

The work hardening rate can be calculated from the slope of the experimental true stress-true strain curves in the work hardening stage. Recrystallization activation energy can be expressed as [27],

$Q_{\mathrm{act}}=n R \frac{d\left\{\ln \left[\sinh \left(\alpha \sigma_{\mathrm{p}}\right)\right]\right\}}{d\left(\frac{1}{T}\right)}$

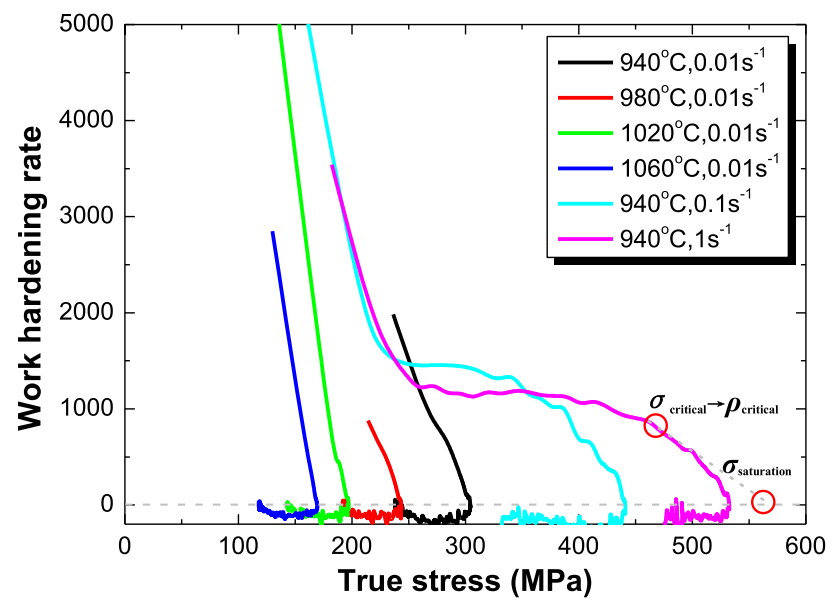

Fig. 6 Hardening rate curves under different temperatures and strain rates where $R$ is the gas constant, $\alpha$ is constant, $\sigma_{\mathrm{p}}$ is the peak stress, $T$ is the temperature. The value of $n$ can be derived from the slope in a plot of the value of $\ln \left[\sinh \left(\alpha \sigma_{\mathrm{p}}\right)\right]$ as a function of $\ln \dot{\varepsilon}$. $Q_{\text {act }}$ can be derived from the slope in a plot of $\ln \left[\sinh \left(\alpha \sigma_{\mathrm{p}}\right)\right]$ as a function of $1 / T$. The value of $Q_{\text {act }}$ is $430 \mathrm{~kJ} / \mathrm{mol}$.

\subsection{Reverse method of determination of nucleation parameter}

The intrinsic information of DRX such as nucleation and growth of the new recrystallized grain is embedded in the material flow stress. The optimal values of nucleation parameter can be identified when the difference between the measured and calculated stress-strain curves is minimized. Essentially, it is a minimization problem and the minimization objective function can be defined as:

$f(x)=\sum_{k=1}^{N}\left(\frac{\sigma_{k}^{\mathrm{cal}}(x)-\sigma_{k}^{\exp }}{\sigma_{k}^{\exp }}\right)^{2}$

where $\sigma_{k}^{\text {exp }}$ and $\sigma_{k}^{\text {cal }}(x)$ are experimental and calculated flow stresses at the strains $\varepsilon_{\mathrm{k}}(k=1, \ldots, N)$, respectively. $N$ is the number of sampling points on the stress-strain curve and $x$ is the nucleation parameters $\left(C_{\text {dynamic }}\right)$ to be identified. Table 2 shows the values obtained from flow stress curves.

\section{Simulation results and discussion}

In the developed CA model, the simulation mesh is $512 \times 512$ square lattice, and periodic boundary conditions are used. The size of every cell represents $2 \mu \mathrm{m}$ of the real dimension of the material. In order to balance the accuracy and computational efficiency, the increment of strain is 0.2 during coupling with the effect of grain morphology change on DRX. Figure 7 shows a comparison of predicted true stress-strain curve and experimental one. It also gives the microstructural evolution of DRX at a strain rate of $1 \mathrm{~s}^{-1}$ and temperature of $1060{ }^{\circ} \mathrm{C}$ with consideration of grain morphology deformation. The different color regions represent the recrystallized grains, and the orange regions denote the deformed matrix, and the black lines denote the grain boundaries (GBs). The initial microstructure $\left(D_{0}=210 \mu \mathrm{m}\right)$ is obtained by running the initial microstructural generation module. As shown in the figure, the grains that have not completed the DRX in each round are compressed in the vertical direction with the continuous deformation, and the newly formed recrystallized grains grow with the type of equiaxed growth in the cellular coordinate system. The recrystallized fraction increases with the increase in the strain from 0.62 to 0.93 . 
Table 2 Values of CA simulation parameters

\begin{tabular}{llrlll}
\hline Deformation conditions & \multicolumn{1}{l}{$k_{1}$} & \multicolumn{1}{l}{$k_{2}$} & $N_{\text {dynamic }}\left(1 / \mathrm{s} \mathrm{cm}^{3}\right)$ & $\sigma_{\text {saturation }}(\mathrm{MPa})$ & $\rho_{\text {critical }}\left(1 / \mathrm{cm}^{2}\right)$ \\
\hline $940{ }^{\circ} \mathrm{C}, 0.1 \mathrm{~s}^{-1}$ & $1.2821 \mathrm{E} 09$ & 27.1871 & $5.5243 \mathrm{E} 09$ & 463.2430 & $1.9790 \mathrm{E} 15$ \\
$940{ }^{\circ} \mathrm{C}, 0.01 \mathrm{~s}^{-1}$ & $2.6947 \mathrm{E} 09$ & 82.7515 & $1.4916 \mathrm{E} 08$ & 319.8771 & $9.4519 \mathrm{E} 14$ \\
$980{ }^{\circ} \mathrm{C}, 1 \mathrm{~s}^{-1}$ & $1.0800 \mathrm{E} 09$ & 22.1085 & $1.8085 \mathrm{E} 12$ & 479.8538 & $2.1267 \mathrm{E} 15$ \\
$980{ }^{\circ} \mathrm{C}, 0.1 \mathrm{~s}^{-1}$ & $2.0894 \mathrm{E} 09$ & 55.6877 & $1.1180 \mathrm{E} 10$ & 368.5589 & $1.2335 \mathrm{E} 15$ \\
$980{ }^{\circ} \mathrm{C}, 0.01 \mathrm{~s}^{-1}$ & $3.0019 \mathrm{E} 09$ & 115.1268 & $8.0101 \mathrm{E} 08$ & 256.1323 & $6.1700 \mathrm{E} 14$ \\
$1020{ }^{\circ} \mathrm{C}, 0.1 \mathrm{~s}^{-1}$ & $2.7250 \mathrm{E} 09$ & 86.3023 & $5.5243 \mathrm{E} 10$ & 310.1598 & $8.8970 \mathrm{E} 14$ \\
$1020^{\circ} \mathrm{C}, 0.01 \mathrm{~s}^{-1}$ & $3.2054 \mathrm{E} 09$ & 151.8849 & $5.7747 \mathrm{E} 09$ & 207.3096 & $3.9812 \mathrm{E} 14$ \\
$1060{ }^{\circ} \mathrm{C}, 1 \mathrm{~s}^{-1}$ & $2.1856 \mathrm{E} 09$ & 57.1169 & $2.4402 \mathrm{E} 12$ & 375.8781 & $1.3134 \mathrm{E} 15$ \\
$1060{ }^{\circ} \mathrm{C}, 0.1 \mathrm{~s}^{-1}$ & $3.4035 \mathrm{E} 09$ & 135.0742 & $8.7355 \mathrm{E} 10$ & 247.5122 & $5.7233 \mathrm{E} 14$ \\
$1060{ }^{\circ} \mathrm{C}, 0.01 \mathrm{~s}^{-1}$ & $3.7848 \mathrm{E} 09$ & 208.8075 & $6.0839 \mathrm{E} 10$ & 178.0496 & $2.9599 \mathrm{E} 14$ \\
\hline
\end{tabular}

Fig. 7 Simulated microstructural evolution of DRX with consideration of grain morphology at a strain rate of $1 \mathrm{~s}^{-1}$ and temperature of $1060{ }^{\circ} \mathrm{C}$

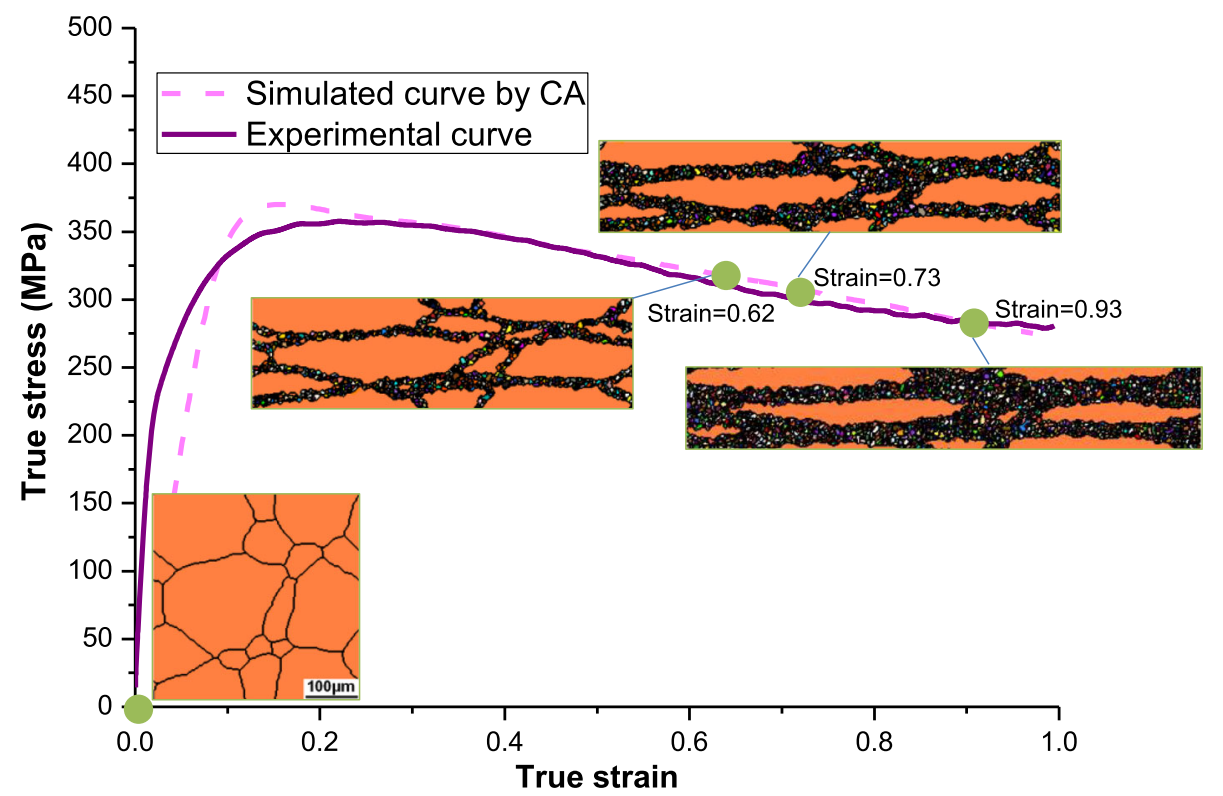

Figure 8 gives the simulated microstructures without considering the grain morphology change of the initial matrix at the temperature of $1060{ }^{\circ} \mathrm{C}$ and the strain rates of 1 and $0.1 \mathrm{~s}^{-1}$, respectively. Figure 9 shows the simulated results by using the CA model with support of the grain morphology technology under the same deformation
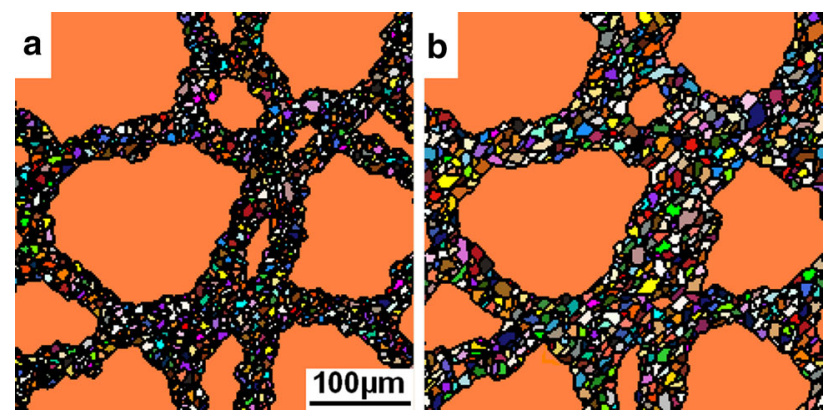

Fig. 8 Simulated microstructures without consideration of grain morphology deformation at temperature of $1060{ }^{\circ} \mathrm{C}$ for different strain rates: a $1 \mathrm{~s}^{-1}$ and $\mathbf{b} 0.1 \mathrm{~s}^{-1}$ conditions. Additionally, Fig. 10 illustrates the simulated average grain size and recrystallized fraction using the topological CA model at a strain rate of 1 and $0.1 \mathrm{~s}^{-1}$ and temperature of $1060{ }^{\circ} \mathrm{C}$ in comparison with the conventional CA simulation. Overall, there is a reasonable agreement between the final average grain size in CA simulations and experiments from Figs. 8 and 11. Meanwhile, the results also show that the grain morphology deformation has an accelerated effect on the recrystallization process. The recrystallized fractions are 89 and $75 \%$ for the strain rates of 0.1 and $1 \mathrm{~s}^{-1}$, respectively, when the grain morphology deformation technique was adopted as compared to only 58 and $46 \%$ of recrystallized fractions without the consideration of grain morphology deformation. The simulation results also indicate that the simulated average grain size decreases slightly due to the effect of matrix deformation. The reason for such a difference may be because that the elongated grain boundaries provide more potential nucleation sites for recrystallization due to a higher ratio of the grain boundary volume to grain volume. 

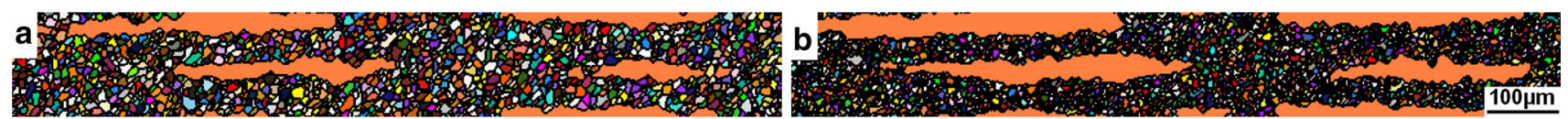

Fig. 9 Simulated microstructures with consideration of grain morphology deformation at temperature of $1060{ }^{\circ} \mathrm{C}$ for different strain rates: a $0.1 \mathrm{~s}^{-1}$ and $\mathbf{b} 1 \mathrm{~s}^{-1}$

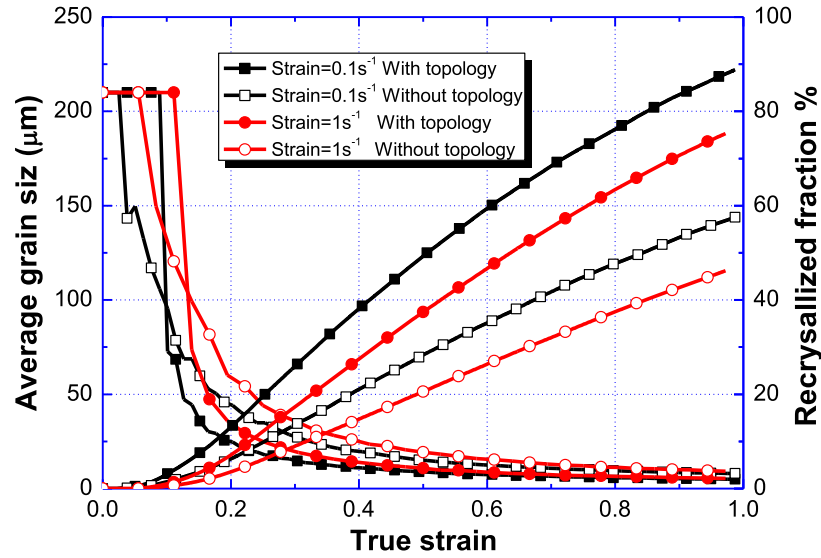

Fig. 10 Simulated kinetic curves of DRX using the topological CA model at a temperature of $1060{ }^{\circ} \mathrm{C}$ and strain rates of 0.1 and $1 \mathrm{~s}^{-1}$, and a comparison with the conventional $\mathrm{CA}$ simulation result

At the same time, the newly formed recrystallized grains impinge earlier with support of the morphology change of the matrix, resulting in a smaller average grain size as compared to the conventional CA simulation [5-18]. In addition, it can be also found that the grain morphology deformation has a decreased effect on the critical strain for DRX. The reason may be due to that the reduction in the initial grain size/matrix accelerates the progress of DRX [5]. In conclusion, the CA model with the incorporation of the morphology deformation technique can better reflect the topological characteristics of the deformed grains in the simulation of DRX.

Figure 11 shows the simulated microstructures of IN718 superalloy under different thermomechanical conditions. The average size of the DRX grains increases from 2 to $12 \mu \mathrm{m}$ with the temperature increases from 940 to $1020{ }^{\circ} \mathrm{C}$. The average grain size increases from 5 to $8 \mu \mathrm{m}$ with strain rate decreasing from 0.01 to $0.001 \mathrm{~s}^{-1}$. It is obvious that decrease in temperature and/or increase in strain rate can refine the DRX grain size. The influences of
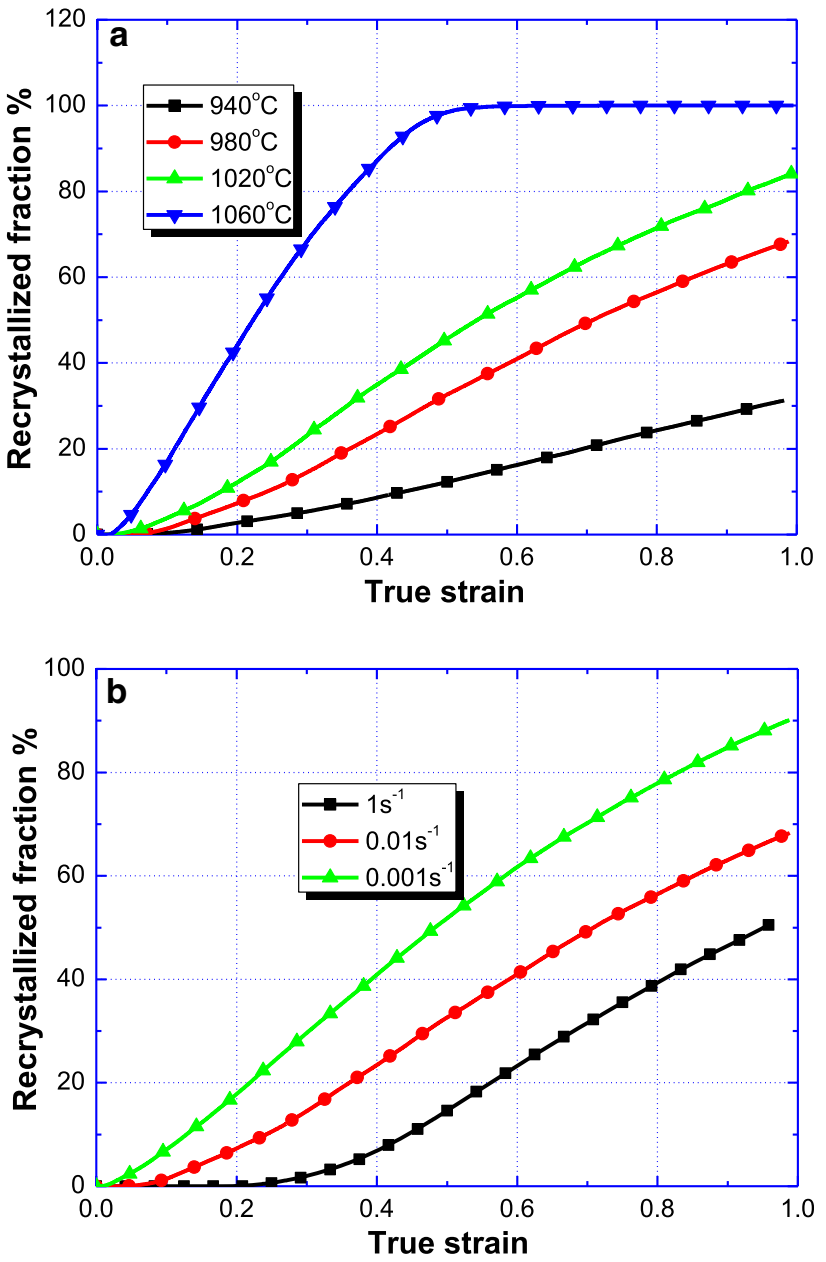

Fig. 12 a Simulated kinetic curves of DRX at the strain of 1 and strain rate of $0.01 \mathrm{~s}^{-1}$, and $\mathbf{b}$ simulated kinetic curves of DRX at the strain of 1 and temperature of $980{ }^{\circ} \mathrm{C}$

the strain rate and the temperature on the DRX kinetics are presented in Fig. 12. Figure 12a shows the DRX kinetics at different temperatures under the strain rate of $0.01 \mathrm{~s}^{-1}$, while Fig. $12 \mathrm{~b}$ shows the DRX kinetics at $980{ }^{\circ} \mathrm{C}$ under
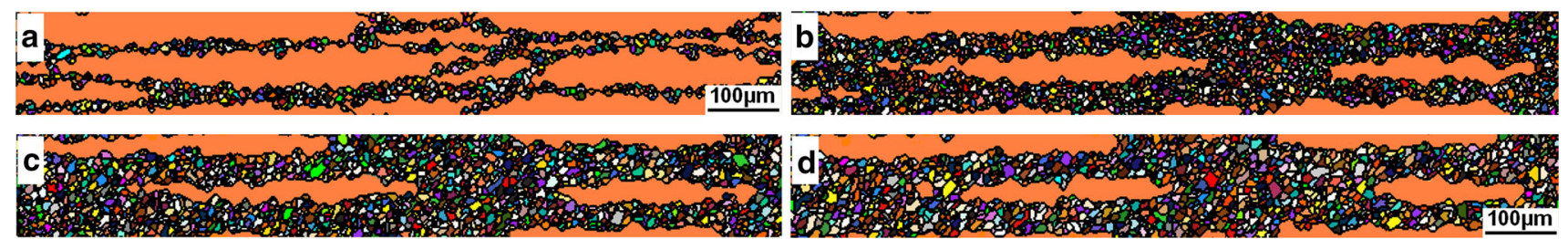

Fig. 11 CA simulated microstructures of IN718 superalloy at a strain rate of $0.01 \mathrm{~s}^{-1}$ and a strain of 1 coupling with the grain morphology technology, the temperatures are: a $940{ }^{\circ} \mathrm{C}, \mathbf{b} 980{ }^{\circ} \mathrm{C}$ and c $1020{ }^{\circ} \mathrm{C}$. And d at temperature of $980{ }^{\circ} \mathrm{C}$ and strain rate of $0.001 \mathrm{~s}^{-1}$ 

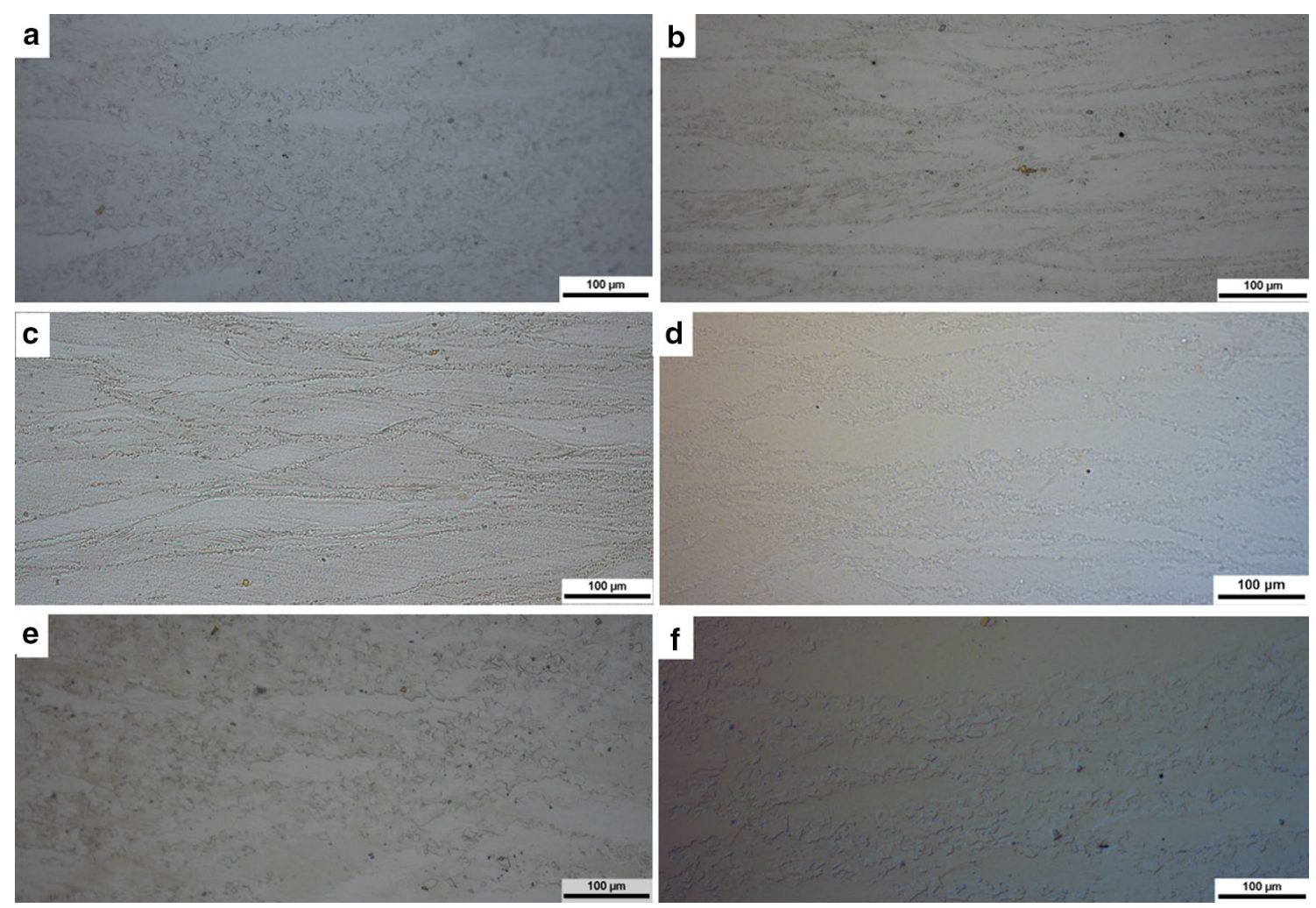

Fig. 13 Effect of strain rate on microstructures $(\times 200)$ of IN718 superalloy deformed at the temperature of $1060{ }^{\circ} \mathrm{C}$ and strain of 1.0 with strain rates of $\mathbf{a} 0.1 \mathrm{~s}^{-1}$ and $\mathbf{b} 1 \mathrm{~s}^{-1}$. Effect of temperature on

microstructures of IN718 superalloy deformed at the strain rate of $0.01 \mathrm{~s}^{-1}$ and temperatures of $\mathbf{c} 940^{\circ} \mathrm{C}, \mathbf{d} 980{ }^{\circ} \mathrm{C}$ and e $1020^{\circ} \mathrm{C}$. And f at the temperature of $980{ }^{\circ} \mathrm{C}$ and strain rate of $0.001 \mathrm{~s}^{-1}$

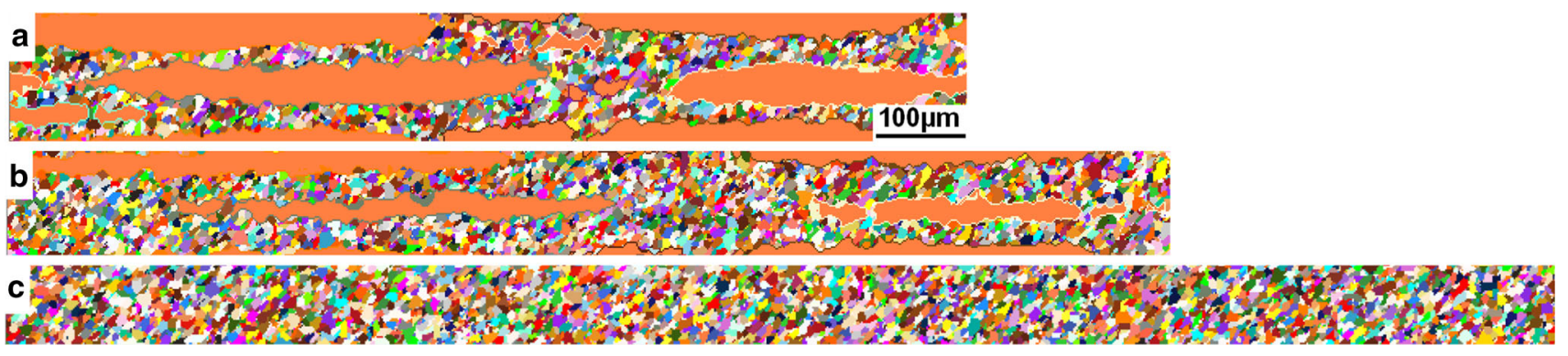

Fig. 14 Prediction of microstructure evolution at a broad range of strain and the temperature of $940{ }^{\circ} \mathrm{C}$ and strain rate of $0.001 \mathrm{~s}^{-1}$. $\mathbf{a} \varepsilon=1, \mathbf{b}$ $\varepsilon=1.2$ and $\mathbf{c} \varepsilon=1.5$

different strain rates. It is clear that only when the strain reaches a critical value, DRX can occur at a certain temperature and strain rate under hot deformation. In other words, there is a need for time-dependent deformation to initiate DRX. Also, this time-dependent deformation would account for the incubation period that was observed by Fisher et al. [33]. From these figures, we can also observe that increasing the temperature and/or decreasing the strain rate can reduce the incubation period. This phenomenon is mainly attributable to the rate of dislocation accumulation and the critical strain. The faster the rate of dislocation accumulation and the smaller the critical strain, hence the shorter the incubation time.
Figure 13a, b shows the grain microstructures in the deformed specimens under temperature of $1060{ }^{\circ} \mathrm{C}$ and strain rates of 0.1 and $1 \mathrm{~s}^{-1}$, respectively. Figure 13d, f shows the grain microstructures in the deformed specimens under temperature of $980{ }^{\circ} \mathrm{C}$ and strain rates of 0.01 and $0.001 \mathrm{~s}^{-1}$. Under the relatively low strain rate, the equiaxed and homogeneous grains are dominant (shown in Fig. 13a, f). Meanwhile, it can be found that number of DRX grains obviously decreases under the strain rate of $1 \mathrm{~s}^{-1}$, and the elongated original grains is shown easily in Fig. 13b. Also, it reveals that some fine DRX grains preferentially nucleate at the vicinities of grain boundaries. From Fig. 13a, b, d and f, it can be found that the DRX 
grains become fine, while there are still some original coarse grains under the high strain rate. Figure $13 c, d$ and e shows the grain microstructures in the deformed specimens under 940,980 and $1020{ }^{\circ} \mathrm{C}$, respectively. Here, the true strain and strain rate are 1 and $0.01 \mathrm{~s}^{-1}$, respectively. It is clearly seen that the grain microstructures are greatly dependent on the deformation temperature. Under the relatively low temperature $\left(940{ }^{\circ} \mathrm{C}\right)$, there are many elongated original grains, but only a few DRX grains, as shown in Fig. 13c, and the recrystallized grain size is less than $2 \mu \mathrm{m}$. When the deformation temperature increases to $980{ }^{\circ} \mathrm{C}$, some equiaxed DRX grains appear and the average recrystallized grain size can be estimated as $6-8 \mu \mathrm{m}$, as shown in Fig. 13d. Under the deformation temperature of $1020{ }^{\circ} \mathrm{C}$, the fraction volume of recrystallized DRX grains increases greatly and the grain microstructure is notably reined (shown in Fig. 13e). As compared with the CA simulated microstructures (shown in Figs. 9 and 11), the simulated recrystallized DRX grain size values are slightly higher than the experimental values. The main reason may conclude that the modified CA simulation did not consider the effect of precipitation phases such as $\gamma^{\prime}, \gamma^{\prime \prime}$ and $\delta$ on the DRX behavior of Ni-based superalloy [34].

Figure 14 shows the microstructural evolution during large strain deformation. As shown in the figure, when the strain reaches 1.0 , the recrystallized fraction is less than $50 \%$, when the strain reaches 1.5 , complete recrystallization takes place, and the initial grains are refined greatly. It is well known that one of the typical characteristic of severe plastic deformation (SPD) is refining the grain size through the large deformation [35]. Therefore, CA method is capable of predicting microstructural evolution for DRX of IN718 superalloy in SPD process such as multi-direction forging.

\section{Conclusions}

In this paper, the 2D CA model was developed to study on the DRX behaviors of IN718 superalloy. The main conclusions can be summarized as follows:

(1) By introducing the mechanism of morphology change of grain, a CA model was established to describe the DRX for IN718 superalloy. At the same time, the reverse method was adopted to identify the nucleation parameter. The CA model is shown to be a new and powerful tool for quantitative and explicit simulation of microstructural evolution during DRX. The established CA model can well describe the DRX behaviors of the studied superalloy. Furthermore, the developed CA model can also be used as an efficient simulation method to investigate the microstructural evolution in large material deformation on a mesoscale under the conditions such as multi-direction forging for IN718 superalloy.

(2) The effects of deformation temperature and strain rate on the recrystallized grain size are significant. Increasing the deformation temperature or decreasing the strain rate coarsens the recrystallized grain size. DRX is difficult to take place under the relative low temperature $\left(900{ }^{\circ} \mathrm{C}\right)$. At a relative low strain rate of $0.001 \mathrm{~s}^{-1}$ and temperature higher than $980{ }^{\circ} \mathrm{C}$, it is easier for full DRX to take place.

Acknowledgments This work was supported by the Engineering and Physical Science Research Council of UK (EP/L02084X/1), the Marie Curie International Incoming Fellowship (628,055\&913,055), International Research Staff Exchange Scheme (IRSES, MatProFuture project, 318,968 ) within the 7th European Community Framework Programme (FP7), National Basic Research Program of China (Grant No. 2011CB012903) and National Science and Technology Major Project (Grant No. 2012ZX04012-011).

Open Access This article is distributed under the terms of the Creative Commons Attribution 4.0 International License (http://creative commons.org/licenses/by/4.0/), which permits unrestricted use, distribution, and reproduction in any medium, provided you give appropriate credit to the original author(s) and the source, provide a link to the Creative Commons license, and indicate if changes were made.

\section{References}

1. X.Y. Niu, Y.J. Yu, L.H. Ma, L.B. Chen, Experimental study on the dynamic mechanical properties of titanium alloy after thermal oxidation. Appl. Phys. A 122, 597 (2011)

2. L. Meng, M.H. Wang, X. Liu, F.L. Wang, Hot compression deformation behavior and a modified physically-based constitutive model of Cu-6\%Ag alloy. Appl. Phys. A 122, 387 (2016)

3. G.Z. Quan, G.C. Luo, J.T. Liang, D.S. Wu, A. Mao, Q. Liu, Modelling for the dynamic recrystallization evolution of Ti-6Al$4 \mathrm{~V}$ alloy in two-phase temperature range and a wide strain rate range. Comput. Mater. Sci. 97, 136-147 (2015)

4. R.L. Goetz, V. Seetharaman, Modeling dynamic recrystallization using cellular automata. Scr. Mater. 38, 405-413 (1998)

5. R. Ding, Z.X. Guo, Coupled quantitative simulation of microstructural evolution and plastic flow during dynamic recrystallization. Acta Mater. 49, 3163-3175 (2001)

6. D. Raabe, Cellular automata in materials science with particular reference to crystallization simulation. Annu. Rev. Mater. Res. 32, 53-76 (2002)

7. G. Kugler, R. Turk, Modeling the dynamic recrystallization under multi-stage hot deformation. Acta Mater. 52, 4659-4668 (2004)

8. C.W. Zheng, N.M. Xiao, D.Z. Li, Y.Y. Li, Microstructure prediction of the austenite recrystallization during multi-pass steel strip hot rolling: a cellular automaton modelling. Comput. Mater. Sci. 44, 507-514 (2008)

9. Z.Y. Jin, Z.S. Cui, Investigation on strain dependence of dynamic recrystallization behavior using an inverse analysis method. Mater. Sci. Eng. A 527, 3111-3119 (2010)

10. N. Yazdipour, C.H.J. Davies, P.D. Hodgson, Microstructural modeling of dynamic recrystallization using irregular cellular automata. Comput. Mater. Sci. 44, 566-576 (2008) 
11. H. Hallberg, M. Wallin, M. Ristinmaa, Simulation of discontinuous dynamic recrystallization in pure $\mathrm{Cu}$ using a probabilistic cellular automaton. Comput. Mater. Sci. 49, 25-34 (2010)

12. H.L. Ding, L.F. Liu, S. Kamado, W.J. Ding, Y. Kojima, Investigation of the hot compression behavior of the Mg-9Al-1Zn alloy using EBSP analysis and a cellular automata simulation. Model. Simul. Mater. Sci. Eng. 17, 025009 (2009)

13. F. Chen, Z.S. Cui, J. Liu, X.X. Zhang, W. Chen, Modeling and simulation on dynamic recrystallization of $30 \mathrm{Cr} 2 \mathrm{Ni} 4 \mathrm{MoV}$ rotor steel using cellular automaton method. Modelling Simul. Mater. Sci. Eng. 17, 075015 (2009)

14. F. Chen, Z.S. Cui, Mesoscale simulation of microstructure evolution during multi-stage hot forging processes. Model. Simul. Mater. Sci. Eng. 20, 045008 (2012)

15. Y. Zhi, X.H. Liu, H.L. Yu, Cellular automaton simulation of hot deformation of TRIP steel. Comput. Mater. Sci. 81, 104-112 (2014)

16. A. Timoshenkov, P. Warczok, M. Albu, J. Klarner, E. Kozeschnik, R. Bureau, C. Sommitsch, Modelling the dynamic recrystallization in $\mathrm{C}-\mathrm{Mn}$ micro-alloyed steel during thermomechanical treatment using cellular automata. Comput. Mater. Sci. 94, 85-94 (2014)

17. C. Wu, H. Yang, H.W. Li, Modeling of discontinuous dynamic recrystallization of a near- $\alpha$ titanium alloy IMI834 during isothermal hot compression by combining a cellular automaton model with a crystal plasticity finite element method. Comput. Mater. Sci. 79, 944-959 (2013)

18. Y.C. Lin, Y.X. Liu, M.S. Chen, M.H. Huang, X. Ma, Z.L. Long, Study of static recrystallization behavior in hot deformed $\mathrm{Ni}$ based superalloy using cellular automaton model. Mater. Des. 99, 107-114 (2016)

19. X.M. Chen, Y.C. Lin, M.S. Chen, H.B. Li, D.X. Wen, J.L. Zhang, M. He, Microstructural evolution of a nickel-based superalloy during hot deformation. Mater. Des. 77, 41-49 (2015)

20. S.C. Medeiros, Y.V.R.K. Prasad, W.G. Frazier, R. Srinivasan, Microstructural modeling of metadynamic recrystallization in hot working of IN 718 superalloy. Mater. Sci. Eng. A 293, 198-207 (2000)

21. M.J. Zhang, Z.Y. Gao, J.Y. Zhuang, Z.Y. Zhong, Grain growth model of IN718 during holding period after hot deformation. J. Mater. Process. Technol. 101, 25-30 (2000)

22. C.M. Kuo, Y.T. Yang, H.Y. Bor, C.N. Wei, C.C. Tai, Aging effects on the microstructure and creep behavior of Inconel 718 superalloy. Mater. Sci. Eng. A 510-511, 289-294 (2009)
23. Y.C. Lin, X.M. Chen, D.X. Wen, M.S. Chen, A physically-based constitutive model for a typical nickel-based superalloy. Comput. Mater. Sci. 83, 282-289 (2014)

24. Y.C. Lin, J. Deng, Y.Q. Jiang, D.X. Wen, G. Liu, Hot tensile deformation behaviors and fracture characteristics of a typical Nibased superalloy. Mater. Des. 55, 949-957 (2014)

25. Y.C. Lin, J. Deng, Y.Q. Jiang, D.X. Wen, G. Liu, Effects of initial $\delta$ phase on hot tensile deformation behaviors and fracture characteristics of a typical Ni-based superalloy. Mater. Sci. Eng. A 598, 251-262 (2014)

26. F. Chen, J. Liu, H. Ou, Z.S. Cui, H. Long, Flow characteristics and intrinsic work ability of IN718 superalloy. Mater. Sci. Eng. A 642, 279-287 (2015)

27. H. Mecking, U.F. Kocks, Kinetics of flow and strain-hardening. Acta Metall. 29, 1865-1875 (1981)

28. Y. Estrin, H. Mecking, A unified phenomenological description of work hardening and creep based on one-parameter models. Acta Metall. 32, 57-70 (1984)

29. V. Marx, F.R. Reher, G. Gottstein, Simulation of primary recrystallization using a modified three-dimensional cellular automaton. Acta Mater. 47, 1219-1230 (1999)

30. F. Chen, Z.S. Cui, J. Liu, W. Chen, S. Chen, Mesoscale simulation of the high-temperature austenitizing and dynamic recrystallization by coupling a cellular automaton with a topology deformation technique. Mater. Sci. Eng. A 527, 5539-5549 (2010)

31. C.M. Sellars, Q. Zhu, microstructural modelling of aluminium alloys during thermomechanical processing. Mater. Sci. Eng. A 280, 1-7 (2000)

32. N. Zhou, D.C. Lv, H.L. Zhang, D. McAllister, F. Zhang, M.J. Mills, Y. Wang, Computer simulation of phase transformation and plastic deformation in IN718 superalloy: microstructural evolution during precipitation. Acta Mater. 65, 270-286 (2014)

33. R. Fisher, L. Darken, K. Carroll, Accelerated growth of tin whiskers. Acta Metall. 2, 368-373 (1954)

34. X.M. Chen, Y.C. Lin, D.X. Wen, J.L. Zhang, M. He, Dynamic recrystallization behavior of a typical nickel-based superalloy. Mater. Des. 57, 568-577 (2014)

35. A. Mishra, B.K. Kad, F. Gregori, M.A. Meyers, Microstructural evolution in copper subjected to severe plastic deformation: experiments and analysis. Acta Mater. 55, 13-28 (2007) 